\title{
Friendships worth fighting for: bonds between women and men karate practitioners as sites for deconstructing gender inequality
}

Chloe MacLean

This is an Accepted Manuscript of a book chapter published by Routledge in Sex Integration in Sport and Physical Culture: Promises and Pitfalls on 11 October 2018, available online: 


\title{
Friendships worth fighting for: Bonds between women and men karate practitioners as sites for deconstructing gender inequality?
}

\author{
Sport is argued to be one of the few remaining domains for constructing \\ masculine identity and reproducing ideas of men's (hierarchical) distinction from \\ women. As a shared emotional (yet 'masculine') experience sport lays the \\ grounds for building close, intimate, friendships which, in men's single-sex sport, \\ are suggested to be underpinned by sharing sexist ideology. This paper argues \\ that sex-integrated karate practice not only challenges the expectations \\ /interpretations of women's bodies, but can also situate women and men within \\ mutually respectful, cherished relationships which diverge from conventional \\ sexualized and unequal ways of 'doing gender' in mixed-sex relationships.
}

Keywords: karate; friendship; mixed-sex; gender; intimacy

\section{Introduction}

Sport is argued to be a key arena for constructing masculine identity and reproducing ideas of men's (hierarchical) distinction from women, and the ensuing subordination of women and femininity (Burstyn, 1999; Connell, 1990; 2012; Hargreaves, 1994). It is also recognized and enjoyed as a field founded on generating, encouraging, and amplifying emotions (Elias and Dunning, 1986). As a shared physical and emotional (yet 'masculine') experience, participation in sport lays the grounds for building intimate friendships. Yet there remains little sociological investigation into friendships in sport: how they are crafted, who they are crafted between, how gender is constructed/performed within these sporting relations, their role in recreating or challenging ideas of women's subordination to men.

Ways of doing our relationships are embedded with ways of 'doing gender' (West and Zimmerman, 1987; Jamieson, 1997). Doing gender is a social, interactive, act, done relationally to the specific setting and people present, and embedded with ways of performing differences that re/create the distinct categories of man and woman 
(West and Zimmerman, 1987). The perceived differences between what it is to 'be a man' and what it is to 'be a woman' not only entail distinct expectations of what women and men should do and how they should present themselves in social situations, but are also used to legitimise a gender hierarchy that subordinates women, and what women do (Connell, 2009). As a woman doing gender thus entails doing/being subjected to subordination. The extent to which our relationships reflect traditional, hierarchically distinct, ways of doing gender vary - some relationships may strongly recreate notions of difference that subordinate women, whilst others might render certain notions of difference unviable, and in the process, begin to 'undo' gender (Deutsch, 2007). As such, how we 'do' our relationships can impact the extent to which we recreate a gender hierarchy that subordinates women.

In comparison to family, work, or couple relationships, friendships are argued to be freer in form, with greater emphasis on mutual negotiation of terms and interactions of the relationship (Budgeon, 2006). Friendships are deemed to be freely chosen (or terminated), less bound by social norms, expectations, and hierarchical power relations than our family or couple relationships (Allan, 2005), and characterized by fun, trust, mutual respect, and reciprocal 'work' or 'giving' to the relationship (Budgeon, 2006). As a relationship privileging mutual negotiation over hierarchically structured (and gendered) expectations, friendships theoretically offer space where gendered scripts of interaction can be renegotiated (Jamieson, 1997). Friendships between women and men particularly hold potential to challenge notions of hierarchical difference between women and men through challenging conventional (hierarchical) ways of doing gender in woman-man relationships. Yet despite friendship's more negotiable form, current literature points towards the tendency to befriend people similar to ourselves, with a strongly sex-segregated pattern that predominates most friendships (Belot, 2009; 
Davies, 2011; Jamieson, 1997). If our friendships - the relationship of choice, equality and negotiation - are held predominantly with people of the same sex as us, then our ability to challenge hierarchically distinct notions embedded in ways of doing gender relationally with members of the opposite sex is limited.

Sport is an amplified arena for constructing ideas of gender difference: it plays a central role in attaching meanings of triumph, strength, weakness and fragility to the sexed body, thus aligning bodies more or less to masculinity or femininity (Connell, 1990); It is predominantly practiced sex-segregated, reiterating ideas that men and women require separated practice due to differences in ability/desires in sport (McDonagh and Pappano, 2008); and is disproportionately dominated by men - from club practice to coaching/managerial roles to ownership/investment - constructing sport as a male domain and something intrinsic to masculine identity (Burstyn, 1999), but not feminine identity. However, precisely because of sports association to masculinity, as growing numbers of women enter the field it is an arena oozing challenges to conventional ideas of women's bodies and the exclusivity of characteristics previous deemed masculine to men's bodies (for example see: Anderson, 2008; Dworkin and Messner, 2002; McNaughton 2012).

As the majority of sports are practiced sex-segregated, the ability to generate cross-sex friendships in sport remains limited, and with this, opportunities to renegotiate ways of doing gender interactively with members of the opposite sex are also limited. In men's team sport, the sex segregated set up is argued to not only take away the opportunity for men and women to generate sporting friendships, but actively places sharing sexist attitudes towards women at the foundations of building and performing friendships with male teammates (Anderson, 2008; Curry, 1991; Pratt, 2000). If friendships are characterized by potential to mould more equal relationships, but remain 
relatively uncommon between men and women (Belot, 2009; Davies, 2011; Jamieson, 1997), and friendships between men in sport are actively founded in sexism, then spaces where friendships between men and women in sport do develop, and how these develop, are of great value in pointing to mechanisms of bridging more equal relations between women and men, and challenging the societal subordination of women ${ }^{1}$.

Mixed-sex combat sports have been highlighted as key arenas challenging ideas of gender difference by placing women and men in direct bodily combat with one another where they must negotiate their interactions. In this space women and men reconceptualise ideas about women's bodies and bodily capabilities (McCaughey, 1997; McNaughton 2012), and ability to fight with men (Channon and Jennings, 2013; Guerandel and Mennesson, 2007; Maclean, 2015). As such, the ways in which men and women 'do' gender in mixed-sex martial arts diverge from conventional notions of gendered interactions, and as such, disrupt the expected gendered power dynamic embedded in men and women's interactions.

Karate is a sex-integrated combat sport utilizing kicks punches and throws, with intensified emotional excitement due to its close-spaced, fast-paced, sweaty body-tobody practice. Although men and women compete separately, and men do still dominate coaching and organizing roles, training is integrated, with an embedded philosophy of respect for ones level in the sport reflected by belt colour. Currently, there is debate about the implications of sex-segregated competition upon the value given to women in sport, and their (hierarchical) relations with men (Space does not allow for a thorough

\footnotetext{
1 This is not to argue that mixed-sex friendships, or mixed-sex sports practice, completely eradicate gender hierarchies, rather that they pose challenges to gender stereotypes, and under certain circumstances, challenge such hierarchies (for more on this debate see: Channon and Jennings, 2013; Hay, 2000; Henry and Comeaux, 1999; Lynch, 2010; Guerandel and Mennesson, 2007)
} 
discussion of this to take place here, please see Maclean, 2015; McDonagh and Pappano, 2008; Guerandel and Mennesson, 2007; Henry and Comeaux, 1999), however, in karate's mixed sex training the embedded respect for higher-level practitioners allows for women to be seen, accepted, and respected as better than some men (Channon, 2013; MacLean, 2015). Within this arena men and women train together, spar together, hurt together, laugh together, contend directly with one-another for sporting capital (Maclean, 2015), and in doing so, do indeed build close emotional friendships. This article seeks to add insight to the matrix of ways in which mixed-sex sports training can challenge ideas of gender by illuminating some key ways in which mixed-sex friendships are made in karate training, and how these in turn pull into question conventional ideas of hierarchically 'doing gender'.

\section{Methodology}

Data presented and discussed in this article is drawn from a six-month ethnographic emersion into three karate clubs (two in Scotland, one in the north of England), alongside 17 years of participation in the sport. The ethnographic study involved 'observant participation' (Wacquant, 2004:8) of club training at least once per week at each club, alongside 15 photo-elicitation interviews (6 men, 9 women) spread evenly across the three clubs.

The photographs discussed in the individual photo-elicitation interviews were taken by the participants with the aim of reflecting their experiences of karate - what I had termed in the studies information leaflet 'photographing 'the good, the bad, and the ugly' of karate'. These photographs were then discussed in one-to-one interviews allowing the participant and their photographs to lead the conversation (Wang, 1999), and room for myself to intersperse discussion of the photos with questions to further 
illuminate how gender was (or was not) entwined with each photographed topic.

Friendship emerged as a theme photographed and brought to discussion by almost all interview participants. Observant participation of the different clubs post-interviews allowed for exploration of how the ideas of friendships in karate discussed in the interviews were actively done in practice. Observations gathered in field notes previous to the interviews were reviewed, participants names given pseudonyms, and coded for friendship. The theme of friendship was then coded into smaller subsections.

Drawn from the map of data gathered on friendship, this article draws on three ways in which mixed-sex friendships are developed and 'done' through karate club training - through sharing an activity together; mutually offering guidance, tips, and support to aid each other's development in karate; and sharing joking 'banter' - and suggests that such friendships hold potential to deconstruct conventional ideas of gender that subordinate, and objectify, women.

\section{Sharing Space, Activity and Passion Together}

In the dojo ${ }^{2}$ a blend of people from different social classes, religions, ages, and genders come together to learn, practice, and improve their karate. All these people spar, sprint, sweat, hit, hurt, learn, and laugh together within the same karate class. Within this mix of karate practitioners, many individuals are placed in a situation where they meet and physically interact with others they would not usually come into contact with. In this space, boundaries and hierarchies that usually divide people's social life by class, race, and gender (Jamieson, 1997), melt away (at least temporarily):

'Karate is great because it's something everybody can do, and when you go into the dojo

\footnotetext{
2 Japanese Term for Karate Hall.
} 
everyone's the same. You might have a Doctor in there who you know is very high up wealthy, highly educated. And then you might have someone else in there, in the same dojo, who's unemployed, or a tradesman, or a student. There are so many variations of people within the dojo on an equal level, I think it brings together people that otherwise wouldn't mix.' Josh.

The tendency to interact, socialize, and befriend other's who are similar to ourselves (Davies, 2011) is stirred by bringing all sorts of people together where, inevitably, they will have to train with one-another at some point - be it in sparring, practicing technique, examining each other's technique, or holding punch bags for one-another. Sharing the experience of doing karate together was seen by karateka ${ }^{3}$ to bridge a privileged understanding of each other:

\footnotetext{
'They know everything about you because I think karate builds you so much as a person that unless someone knows you in that environment, then they don't really know you. And unless you're in it then I don't think you can really understand it.' Rosie.
}

This privileged understanding was seen to build a unified karateka identity that overrode notions of differences between them:

\footnotetext{
'It's like the 'Casa Rosa' - the mafia. It means 'our thing' and with karate it's 'our thing' we all understand each other because it's 'our thing'. So its like, my friends in karate are closer than my friends at work because it's 'our thing', we are training towards the same thing. You're trying to help each other that special bit more.' Keith.
}

Through sharing the exact same physical activity, the same passion, in the same dojo, in

3 Term for karate practitioner. 
the same gender neutral outfit, within intimate interactive proximity, focus shifts from class, race, or gender as central sites of homogeny that enable bonding, to that of being karateka. The shared unisex sports practice provides a counter framework to 'doing gender' (Guerandel and Mennesson, 2008) allowing ideas of differences between women and men to take a secondary position to their similarities as karateka. It is this idea of sharing a karateka identity - of being 'cut from the same cloth' - that sets the foundations for cross-sex friendships to be built:

'I haveny got any female friends outside of karate, I think it's just something programmed into you: Your friends should be men. There's women I was at school with that I'd say hi to and speak to, but I wouldn't class them as friends. But in karate I do. Emma's a friend, Sally's a friend - the women you train with you get close to. You know, you socialize with these folk in class and you get the giggles and the laughs with them.' Keith

Indeed, the unifying ground of sharing an activity, passion, and understanding with members of the opposite sex creates an environment where mixed-sex friendships are viable, and embraced. As Rachel and Scott highlight, for those who have practiced the sport since a young age the idea that there would be a social division between men and women in training seemed particularly obscure and undesirable:

'I think growing up doing karate with guys makes you more comfortable and confident around guys. You don't really think 'oh, I'm training with guys' - you just are. We have a good laugh, we train... I wouldn't have a second thought about it. It's normal for me. I'm comfortable with these guys.' Rachel.

'There's nothing at any point where I think 'oh I should stick with the lads'. Its more 
relaxed, we all chat as you would. I don't see any segregation. I can go up to a woman and just start chatting away, just as a friend - not thinking 'oh your good looking' - ken, nothing like that. It's just an 'Awright, what's the crack?' because at training that's what it is: everyone goes in and mixes - doesn't matter if you're a girl or a guy.' Scott.

As notions of gender difference are dissolved in recognition of, and doing of, a shared karateka identity, a gendered segregation of friendship based on ideas of difference between women and men is challenged, and along with it, a primary understanding of men and women's relationship as a sexual relationship (Jamieson, 1997). Sharing a karateka identity and understanding provides the base for friendships between women and men in karate to be generated.

\section{Helping, Supporting, and learning: Building Practical Intimacy}

As a martial art, a large part of training involves close bodily work with others: to execute techniques, understand how the moves are effective, tweak the positioning of body parts in order to hit the opponent correctly, and in sparring, to playfully use the techniques learnt in creative, fluid, interaction with a sparring partner. The reciprocal intercorporeal helping, supporting, and learning from one-another to aid each other's development as a karateka forms a type of practical intimacy (Jamieson, 1997) ${ }^{4}$ which layers greater depth to the initial mixed-sex friendship-relations of similarity found in karate.

As women and men train together within the club, higher-level karateka intermittently provide advice on technique, tips on movement, and suggestions of

\footnotetext{
${ }^{4}$ The term 'practical intimacy' is not used to suggest that such intimacy involves no emotional elements. Rather it is used in comparison to 'disclosing intimacy' (Jamieson, 1997) - that of reflexively talking about feelings, experiences, and emotions with others.
} 
training drills to lower or equal graded partners. Karate has a deeply embedded hierarchy of respect (Maclean, 2015) which entails that such advice trickles from highest grade downwards. But equally lower grades can, and do, utilize other ways of offering help in the dojo such as: being a target for another; holding pads; sharing equipment; and providing words of encouragement. These offerings of help not only aid the training partner's karate development practically, but also build a bond of being there with another through their emotional journey of a sport they both love:

\footnotetext{
'Some people will say to me 'try this or try that' and I say 'oh thanks, and you should try this or that' And we all try to help each other get better at what we love. It's just such a great thing that all these people go out of their way to help you - where else do you get that?' Sarah.
}

The more two karateka choose to mutually share these aspects of practical help with one-another, the deeper feelings of closeness and affection are created. Karateka tend to pair most frequently with those of the same coloured belt as themselves, and as such, women and men frequently choose to pair with each other in karate due to being placed on the same skill level, where women and men can develop such feelings of closeness. Through interchanges of advice, help, and inspiration developed with training partners, men and women come to learn each other's bodies and capabilities quite intimately, and in ways which challenge conventional ideas of women as passive, fragile, and weak (Maclean, 2015; McNaughton, 2012), and of men as distinctly physically superior and emotionally silent. Women's potential as good training partner's who can physically help, share, and support the development of another's karate is drawn into light, appreciated, and respected: 
'I was training with Emma on Saturday and she just let rip on me, and it was brilliant she can move so quick. So what I focused on was, not hitting hard, but trying to get out of the way quickly with a sweep. So she's coming in full pelt and I'm saying to her brilliant and having a wee shot at sweeping when she's coming in. That helps me because it pushes me, and hopefully the sweeping pushes her.' Alex.

Here women and men are placed on an equal footing as givers and receivers of help, support, and advice. As equal training partners, and equal intimacy providers, a mutual respect for the training partner of the opposite sex is built, as well as an appreciation of the other's support. Part of this supportive role is reading, and being mindful of, the training partner's emotions in order to gauge how to train with them: to fight intensely with them when they are in good spirits; allowing them to score a couple of hits when they need to build confidence; to shout in words of support when they look like they are tiring or need encouragement; or to be prepared to fight hard when they need a break from whatever else is going on in the outside world. These supportive elements were highlighted by all karateka interviewed, but appeared to be particularly appreciated by women when the support was coming from men:

\footnotetext{
'When you're fighting someone you have to give your best, particularly if you're with someone that's good, they... push you, but not in a bad way - like they help you push yourself. And the guys, are like 'come on Alice! Come on Alice!' They always encourage you so much. There's not many places you're with guys together and you're all giving that level of support.' Alice.
}

Friendships between women and men in karate create a space where women and men can, and do, feel and express mutual levels of care. With such mutual levels of respect 
and care are often found missing in women's couple relations with men (Duncombe and Marsden, 1993; Jamieson, 1997), the meaningfulness of men's support of women is amplified. Women's appreciation of men's support reflects feelings of being embraced within caring, respectful, and supportive relations with men, where women are treated equally to the men around them - as fellow karateka.

Together, the physically and emotionally intimate practice of karate challenges conventional ideas of gender difference and ways of doing gender. Through frequent and chosen interchanges of physical help, support, and learning together, women and men karateka form friendships grounded in mutual respect for one another.

\section{Inclusive Banter}

Alongside the elements of practical intimacy characteristic of doing mixed-sex friendships in karate clubs, banter amongst karateka is used to further solidify friendships between men and women in the sport. Joking 'banter' bounces backwards and forwards throughout karate classes, leavening the serious atmosphere of technique work and intense atmosphere of competitive sparring, encouraging an inclusive atmosphere. Such banter is characterized by light-hearted mocking of either self or others, often in regards to: lack of control of techniques; hitting or being hit hard; and ability in comparison to a training partner.

Although the idea of mocking each other might sound at first to represent an emotionally closed off and competitive friendship, it is actually quite the opposite individuals will usually share more banter with those that they feel particularly close to or comfortable with (Plester and Sayers, 2007). Banter in karate works as a mechanism to forge lighthearted unifying bonds by 1 . Sharing an equal and privileged position with everyone else in the club as someone close enough to be playfully mocked; 2 . The 
desire to make others, especially those the banter is directed at, laugh; and 3. Carefully avoiding any sentiments that might actually be hurtful (although this line is sometimes walked very closely).

Banter is often seen to be something characteristic and fundamental to men's friendships with one another - a 'masculine form' of affection expressed through humor - and far less recognized as something embodied in women's friendships (Hay, 2000). Due to it's prominence in men's close friendships with men (Hay, 2000), lack of recognition of women's ability to engage in banter places a barrier between women and men developing feelings of affinity and friendship. Yet in the karate hall, it is something women too are included in, and contribute to:

'There's a lot of banter at karate. I don't know if its just karate or just how I am, but I do have a lot of guy friends, and I like the banter there is with that. I don't know why but some girls (who don't do karate) are afraid to be friends with guys because of the banter they have, but I've never found that.' Alice.

Women's participation in the banter of the karate hall also shapes the type of banter produced, at least temporarily displacing sexualized discussion of women as a form of banter and a way of bonding:

'When I done football it was always lads vs. lads, and it had that, like boyish banter. Ken, talking about girls sometimes, and just stupidness. In karate we still have funny chats, but at football lads would talk about lassies, which, obviously at karate wouldn't happen because lassies are there. But I wouldn't say it's completely different... In football we done sport, had a laugh, got on. In karate, even if its with girls, we talk and have a laugh, and we get to know people quite closely, and like nobody holds back with each other - its 
the same sort of banter and openness.' Scott.

In engaging in cross-sex banter together, women and men are placed on a level (and privileged) playing field to mock, make laugh, and build friendships with. It is an area where women can be publicly funny, silly, and make other's laugh, and in doing so challenge the perception of banter as an exclusively male behavior (Hay, 2000), whilst forging feelings of similarity and solidarity between women and men (Plester and Sayers, 2007). Here, the nature of the banter shifts away from being based on sexist ideas of women. Rather, banter between men and women within the karate club karate often emerges from, or draws upon, the lived contradictory nature of gendered stereotypes:

Keith was fighting with Sarah - a woman feared as a fighter by most in the club due to her intense determination, merciless stamina, and thundering body round kick. I could see out the corner of my eye kick after punch darting at Keith, whilst he tried to find a space to hit Sarah. Coach Alan shouts in 'stop going easy on him Sarah' with a cheeky smile across his face. Sarah laughs and continues to work away whilst Keith jokes back 'Aye, I'm just letting her get all those kicks and punches in! Its not at all that I cant actually see her move because she's so fast!' Stuart joins in laughing at poor Keith, and Sarah shouts 'You're the next victim Stuart!' Field notes.

We were both trying to knock off the other's timing, waiting for the right moment to catch the other out of step and pounce with a face punch. Unfortunately we both chose that moment at the exact same time, and as $6 \mathrm{ft} 2$ '' Blair's arms are a good bit longer than mine, my movement forward was met with his punch. Luckily my nose broke the fall of his punch. Blair stopped for a moment, wide-eyed, unsure how to react, until I burst into fits of giggles. It was like something out of a slapstick comedy - a disaster waiting to 
happen. 'I am the champion!' Blair announces in his laughter. We stayed crunched over giggling, trying to build composure to continue fighting, until the coach shouted for us to change partners. I was, of course, completely fine physically - a bit of a stinging nose, yes, but I wasn't hurt. As we moved onto the next partner we tapped gloves and Blair said 'Where else could me, hitting a woman in the face, cause so much laughter?' Field notes.

Both excerpts above challenge conventional ideas of women as: 1. Fragile and weak 2. Unsuitable for fighting 3. Less skilled than men at fighting. The jokes and laughs which surround these events laugh at the contradictions of such gender stereotypes in relation to the women karateka in the excerpts, and act to reinforce an appreciation of the women as skilled fighters who can hit and be hit (Channon and Jennings, 2013), and as friends close enough to 'take a laugh' and make other's laugh.

\section{Conclusion}

Mixed-sex friendships in karate training offer a unique site for exploring the subversion of gender norms, ideals, and hierarchies. The sex-integrated practice of karate elevates the respect given to women by simultaneously disrupting both ideas of women's bodies as primarily sexual objects subordinate in ability to men (Maclean, 2015), and of men and women as having, offering, and wanting distinctly different qualities in their intimate relations. In focusing on how friendships between women and men are forged in mixed-sex karate practice, this article has suggested that sharing the experience of, and passion for, karate in club training, the gender homogeny characteristic of much sports practice, and many friendships (Belot, 2009;Davies, 2011; Jamieson, 1997), is broken down, allowing for the development of mixed-sex friendships founded on mutual understanding of the other. 
These mixed-sex relationships are turned into friendships through sharing a mutually respectful and respected practical intimacy, and a lighthearted inclusive banter. Such intimacy challenges the idea that men's friendships in sports are purely competitive, lack emotional disclosure, and refrain from showing it (Anderson, 2008; Curry, 1991; Pratt, 2000), notions of women as primary intimacy providers in relationships (Duncombe and Marsden, 1993; Jamieson, 1997), and also of men as exclusive 'expert knowers' in sport (Theberge, 1993). Whilst the inclusive banter thrown between and amongst karateka equally addresses conventional ideas of women's friendships and men's friendships: the former by allowing women a space to be publicly funny, and the latter by 1 . Sharing laughs with women, and 2 . Inadvertently laughing at, rather than laughing because of, sexism towards women. Here, mixed-friendships are built on mutually supportive grounds, with an embedded mutual respect for one-another as athletes and friends.

This is not to suggest that all ideas of gender difference and inequality are washed away in the practice of karate, that all men and women that do karate become best friends with members of the opposite sex, or that there are not gendered elements to the ways in which some of these friendships are made and performed. Indeed, women karateka do lean towards having other women as their strongest friends in the dojo, at times there are elements of men protecting their female karate friends, and of course not everyone who seeks to learn karate wants to make friends. Rather, the purpose of this research insight has been to point to the ways in which, despite sport being a male domain often used to subordinate women (Burstyn, 1999; Connell, 1990; Connell, 2012; Hargreaves, 1994), and friendships predominantly being sexsegregated (Belot, 2009; Davies, 2011; Jamieson, 1997), friendships between women and men in karate are forged, and to illuminate how these relationships can and do 
debunk notions of hierarchical gender distinction.

In karate club training women and men not only generate close, meaningful, and enjoyable friendships, they create friendships which draw into question many conventional notions of (hierarchically) doing gender (West and Zimmerman, 1987), and gendered ways of doing friendship. They choose to form relationships that disembark from expectations of (exclusively) sexual relations between men and women, that avoid jokes or talk that objectifies women, that laugh at such stereotypes of women, that appreciate women's expert advice and encourage men to be mutually supportive, that are grounded in mutual respect, and that are underlined by an understanding each other based on notions of similarity - of being karateka. Men and women's friendship in karate isn't bound by sexism (Curry, 1991), but rather is a friendship that begins to unravel it.

Allan, Graham. 2005. "Boundaries of Friendship." In Families in Society: Boundaries and Relationships, edited by McKie, Linda, and Cunningham-Burley, Sarah, 227-240. University of Bristol: Policy Press.

Anderson, Eric. 2008. “'I used to think women were weak': Orthodox masculinity, gender segregation, and sport.” Sociological Forum 23 (2): 257-280.

Belot, Michelle. 2009. "Gender Differences in Close Friendship Networks over the Life Cycle." In Changing Relationships, edited by Brynin, M, and Ermisch, J, 44-58. London: Routledge. 
Budgeon, Shelley. 2006. "Friendship and formations of sociality in late modernity: The challenge of "post traditional intimacy." Sociological Research Online, 11 (3):

http://www.socresonline.org.uk/11/3/budgeon.html

Burstyn, Varda. 1999. The Rites of Men: Manhood, politics, and the culture of Sport. Toronto: University of Toronto Press.

Channon, Alex. 2013. "Enter the discourse: exploring the discursive roots of inclusivity in mixed-sex martial arts." Sport in Society: Cultures, commerce, media, politics 16(10): 1293-1308.

Channon, Alex, and Jennings, George. 2013. "The rules of engagement: Negotiating painful and 'intimate' touch in mixed-sex martial arts." Sociology of Sport Journal 30: 487-503.

Connell, Raewyn W. 1990. “An Iron Man: The Body and Some Contradictions of Hegemonic Masculinity." In Sport, Men and the Gender Order: Critical Feminist Perspectives, edited by Messner, Michael and Sabo, Donald, 83-96. Champaign Illinois: Human Kinetics.

Connel, Raewyn W. 2009. Gender. Cambridge: Polity Press

Connell, Raewyn W. 2012. "Supremacy and subversion- gender struggles in sport." Asia-Pacific Journal of Health, Sport and Physical Education 3 (3): 177-179. 
Curry, Timothy J. 1991. "Fraternal bonding in the locker room: a profeminist analysis of talk about competition and women." Sociology of Sport Journal 8: 119-135.

Davies, Katherine. 2011. "Friendship and Personal Life." In Sociology of Personal Life, edited by May, Vanessa, 72-84. Basingstoke: Palgrave Macmillan.

Deutsch, Francine M. 2007. "Undoing Gender." Gender and Society 21(1): 106-127.

Duncombe, Jean and Marsden, Dennis. 1993. "Love and Intimacy: The Gender Division of Emotion and 'Emotion Work': A Neglected Aspect of Sociological Discussion of Heterosexual Relationships.” Sociology 27 (1): 221-241.

Dworkin, Steven I. and Messner, Michael A. 2002. "Gender relations in sport." Sociological perspectives 45(4): 347-352.

Elias, Norbert, and Dunning, Eric. 1986. Quest for Excitement: Sport and leisure in the civilizing process. Oxford: Blackwell.

Guerandel, Carine. and Mennesson, Christine. 2007. "Gender construction in judo interactions." International Review for the Sociology of Sport 42 (2): 167-86.

Hargreaves, Jennifer. 1994. Sporting Females: Critical issues in the history and sociology of women's sports. London: Routledge. 
Hay, Jennifer. 2000. "Functions of humor in the conversations of men and women." Journal of pragmatics 32: 709-742.

Henry, Jacques M. and Comeaux, Howard P. 1999. "Gender egalitarianism in coed sport: A case study of American soccer." International Review for the Sociology of Sport 34(3): 277-290.

Jamieson, Lynn. 1997. Intimacy: Personal Relationships in Modern Societies. Cambridge: Polity Press.

Lynch, Owen. 2010. "Cooking with humor: In-group humor as social organisation.” International Journal of Humor Research 23(2): 127-159.

Maclean, Chloe. 2015. "Beautifully Violent: The Gender Dynamic of Scottish Karate." In Global Perspectives on Women in Combat Sports: Women Warriors around the World, edited by Channon, Alex, and Matthews, Christopher. London:Routledge.

McCaughey, Martha. 1997. Real Knockouts: The physical feminism of women's selfdefence. London: New York University Press.

McDonagh, Eileen and Pappano, Laura. 2008. Playing with the boys: Why separate is not equal in sports. New York: Oxford University Press.

McNaughton, Melanie. 2012. "Insurrectionary Womanliness: Gender and the (Boxing) Ring.” The Qualitative Report 17. Article 33: 1-13. 
Plester, Barbara and Sayers, Janet. 2007. “Taking the piss': Functions of banter in the IT industry." Humor 20(2): 157-187.

Pratt, Simon. 2000. "Teenage Kicks: A study of the Construction and Development of Adolescent Masculine Identities in Organised Team Sport.” In Masculinities: Leisure Cultures, Identities and Consumption, edited by Horne, John, and Fleming, Scott, 2338. Britain: Leisure Studies Association.

Theberge, Nancy. 1993. "The Construction of Gender in Sport: Women, Coaching an the Naturalisation of Gender Difference.” Social Problems 40 (3): 201-313.

Wacquant, Louis. 2004. Body and soul: Notebooks of an apprentice boxer. Oxford: Oxford University Press.

Wang, Caroline. 1999. "Photovoice: A participatory Action Research Strategy Applied to Women's health." Journal of women's health 8(2): 185-192.

West, Candice, and Zimmerman, Don. 1987. "Doing Gender." Gender and Society 1(2): $125-151$. 